\title{
De Facto Exchange Rate Regime Classifications: An Evaluation
}

\author{
Michael Bleaney ${ }^{1}$, Mo Tian ${ }^{2}$ and Lin Yin ${ }^{3}$ \\ ${ }^{1}$ School of Economics, University of Nottingham, U.K. \\ ${ }^{2}$ School of Management, Swansea University, U.K. \\ ${ }^{3}$ Emerging Markets Institute, Beijing Normal University, P.R. China
}

\begin{abstract}
There exist several statistically-based exchange rate regime classifications that disagree with one another to a disappointing degree. To what extent is this a matter of the quality of the design of these schemes, and to what extent does it reflect the need to supplement statistics with other information (as is done in the IMF's de facto classification)? It is shown that statistical methods are good at the basics (distinguishing some type of peg from some type of float), but less helpful in other respects, such as determining whether a float is managed, particularly for countries that are not very remote from their main trading partners. Different measures of exchange rate volatility have been used but are not primarily responsible for differences between classifications. The theoretical underpinning of particular classification schemes needs to be more explicit.
\end{abstract}

Keywords: exchange rate regimes, trade, volatility

JEL No.: $\quad$ F31

Word count: 6,579

Acknowledgement

The authors wish to thank the editor, George Tavlas, Alex Mandilaras and an anonymous referee for extremely helpful comments on an earlier version of this paper. Any errors that remain are of course the authors' responsibility.

${ }^{1}$ Corresponding author: Professor M F Bleaney, School of Economics, University of Nottingham, Nottingham NG7 2RD, UK. e-mail: michael.bleaney@ nottingham.ac.uk. Tel. +44 115951 5464. Fax +44 1159514159. Other authors: m.tian@swansea.ac.uk; tclinny@163.com. 


\section{INTRODUCTION}

Accurate identification of the exchange rate regime is important for many reasons. It is required to implement proper empirical tests of theoretical hypotheses, such as the effect of the exchange rate regime on macroeconomic and trade outcomes, or whether the "impossible trinity" holds. Alberola et al. (2016), Erdem and Özmen (2015), Lin and Chu (2013) and Martin (2016) are some recent examples of the routine use of "off-the-shelf" regime classifications in empirical work.

Historically, dissatisfaction with the truth of countries' declared exchange rate regimes led to the development of a variety of alternative classification systems, termed de facto because they relied to a greater or lesser degree on statistical data (see Klein and Shambaugh (2010), Rose (2011) and Tavlas et al. (2008) for detailed surveys). Since 1999 even the IMF has used its own judgement in classifying countries' regimes rather than merely recording what countries claim it to be.

Comparison of the outcomes of these alternative classification systems has revealed that they fail to agree with each other to a disturbing extent (Bleaney and Francisco, 2007; Eichengreen and Razo-Garcia, 2013; Frankel and Wei, 2008; Tavlas et al., 2008). For example Eichengreen and Razo-Garcia (2013), using three regime categories (hard pegs, soft pegs and floats), find pairwise agreement rates between three schemes over the period 19802004 of $60 \%, 69 \%$ and $75 \%$. They also find that disagreements are less common in the advanced countries.

A comparison of outcomes is useful: if all schemes were found to agree closely with one another, then the classifications would look highly robust to differences in the detail of the statistical design. When, as in this case, schemes disagree, it is important to understand how different design features contribute to this result, and to consider how these design features relate to the theoretical analysis of exchange rate regimes (for example, whether the 
main issue is the exchange rate as a shock-absorber or as a nominal anchor), in order to decide which classification is most suitable. The present article is motivated by a perception that there is a significant gap in the literature here. After a discussion of theoretical issues, there follows a forensic analysis of the differences between alternative classifications, which is necessarily somewhat technical. This highlights the differences between the statistics used, the treatment of occasional realignments and the choice of statistical thresholds that function as regime boundaries. The remainder of the article discusses what exactly a purely statistical approach can and cannot be expected to achieve.

The rest of the paper is structured as follows. Section Two discusses theoretical issues. In Section Three, different de facto classification schemes are described and compared. In Section Four, the empirical differences between these classification schemes are analysed. Section Five discusses whether these differences are largely statistical or conceptual. Section Six summarises what a purely statistical analysis can and cannot do, or in other words where it needs to be supplemented by other information. Section Seven concludes.

\section{THEORETICAL ISSUES}

The traditional view of a currency peg is that it is a device that prevents the exchange rate from adjusting freely in response to market forces (e.g. Friedman, 1953). If we adopt this point of view, then a peg may be anchored to either a single currency or a basket of currencies, and the central rate may either be stationary or may crawl to reflect inflation differentials. In all of these cases, what is important is that the exchange rate follows a predetermined path with only minor deviations, and the crucial feature of a peg is low volatility relative to the central rate. 
An alternative approach that has developed in the wake of the rational expectations revolution is to view a pegged exchange rate as a device for committing the authorities to low inflation (Giavazzi and Pagano, 1988). Since devaluation would represent a departure from that commitment, this view would regard the distinction between pegs with devaluations and those without as of critical importance. This point is usually acknowledged as a distinction between "hard" pegs, with stronger than the usual institutional obstacles to devaluation, such as a currency board system or a currency union, and conventional pegs, rather than as one between pegs and non-pegs.

This view of the exchange rate as a potential nominal anchor would also treat crawling pegs as something rather different from horizontal pegs, since crawling pegs effectively target the real rather than the nominal exchange rate. A basket peg (especially if unannounced) might be regarded as a rather weak nominal anchor, because of its relative lack of transparency. In short, the "nominal-anchor" approach would place more emphasis on distinguishing different types of peg than the volatility approach.

A third approach derives from "the impossible trinity" of a pegged exchange rate, uncontrolled international capital movements and monetary independence (e.g. Bleaney et al., 2013; Mandilaras, 2015). With free flows of capital and a commitment to the future path of the exchange rate, interest rates are tied to foreign rates by international arbitrage opportunities. In the case of a horizontal single-currency peg, interest rates must be equal to those in the anchor currency (plus any allowance for expected devaluation); in the case of a crawling peg, the rate of crawl has to be added as well. For basket pegs the relevant foreign interest rate is a weighted average of several currencies. This approach stresses that freedom of capital flows plus monetary independence inevitably imply exchange rate volatility.

It is usual to distinguish between about eight to twelve exchange rate regimes, including the various types of peg mentioned above plus free floats and managed floats. 
Since some of these regimes are thinly populated, it is common in empirical work to aggregate this "fine" classification into a "coarse" classification of two extremes and an intermediate category, the precise definitions depending on the investigator's purpose.

In the remainder of this paper we ask how much can realistically be expected of a purely statistical approach to regime classification. One issue is to identify the right statistic to use. We show that the particular choice of statistic is not the main reason why classifications disagree; rather the critical points are conceptual, such as where to draw the boundary between a peg and a float, and how to treat occasional devaluations.

\section{EXCHANGE RATE CLASSIFICATIONS}

Tavlas et al. (2008) refer to more than ten de facto classification schemes that have been suggested, but quite a few of them have rather limited time or country coverage. We focus on a few schemes that are based exclusively on exchange rate behaviour, and do not take into account other forms of intervention such as movements in foreign exchange reserves (as do Levy-Yeyati and Sturzenegger, 2005). The motivation for adding other variables comes from the literature on currency crises, where the intensity of speculative pressure is a variable of interest. In this case we are not interested in measuring such speculative pressure, but rather in capturing how it is reflected in the exchange rate, irrespective of any other policy measures, so it seems preferable to confine the analysis to exchange rate movements. ${ }^{1}$

The primary criterion for inclusion is data availability, since in the next section we wish to compare the classifications over a large sample of observations; all the classifications used here cover forty years of data for practically every country in the world. The IMF

\footnotetext{
${ }^{1}$ An additional point made by Reinhart and Rogoff (2004) is that not all foreign exchange reserve movements reflect speculative pressures. It is certainly true that floating exchange rates are more volatile at certain periods than at others, which one might ascribe to the intensity of shocks, but the disappointing results of exchange rate models suggest that to model such shocks would be a difficult task.
} 
classification is omitted because the system has changed at various times, as summarized in Klein and Shambaugh (2010, Table 3.1). ${ }^{2}$ In this section we summarise the differences between the schemes (for a more detailed and technical discussion see the Appendix). The three schemes that we focus on are those of Shambaugh (2004), Reinhart and Rogoff (2004) and Bleaney and Tian (2017).

The scheme of Shambaugh (2004) [hereafter termed JS] identifies a country's regime as either a peg or a non-peg in each calendar year. A reference currency is identified. For a peg, the range of the log of the exchange rate against the reference currency must not exceed 0.04 over the calendar year. The one exception is that one exchange rate realignment is allowed, on condition that the log of the exchange rate is unchanged in eleven months out of twelve. Thus effectively the level of the exchange rate is allowed to vary by $\pm 2 \%$, or alternatively by a realignment of any size in one month and $0 \%$ in the remaining eleven months, for a peg to be coded.

The scheme of Reinhart and Rogoff (2004) [hereafter termed RR] is not easily summarised briefly, but it focuses on the tails of the distribution of monthly exchange rate changes against a reference currency. Essentially, for a peg, $80 \%$ of these observations must fall within the range \pm 0.01 . If this criterion is not met, but more than $80 \%$ of observations fall within the range \pm 0.02 , the regime is classified as a band.

The scheme of Bleaney and Tian (2017) [hereafter termed BT] presents a flexibility index based on the root mean square residual (RMSE) from a regression of the change in the $\log$ of the exchange rate against a chosen numéraire currency on the change in the log of the US dollar and of the euro against the same numéraire currency. This regression was originally suggested by Frankel and Wei (1995) for identifying basket pegs. If there is

\footnotetext{
${ }^{2}$ In addition the IMF de facto classification relies on the judgement of officials and is not based purely on a statistical algorithm, which puts it in a somewhat different category.
} 
evidence of a realignment in a given month, the regression is augmented by a dummy for that month and the index recalculated. A threshold value of the flexibility index needs to be chosen in order to define the boundary between pegs and floats; in what follows we use 0.01 as the threshold. The residuals are effectively the movement in the exchange rate relative to the estimated central rate, which is determined by the regression. ${ }^{3}$

These schemes differ in the three crucial aspects of the statistic used to measure volatility, the thresholds between regimes and the treatment of realignments. Realignments can be ignored in the RR scheme, since they are usually too infrequent to make much difference to the proportion of "large" exchange rate movements observed in any period. In BT and JS realignments need to be identified and taken into account; in JS the rules for a peg change if there is a realignment, whereas in BT they do not. In relation to statistical matters, the JS scheme uses a measure of the range of variation of the level of the exchange rate, whereas RR and BT look at exchange rate movements. BT's statistic is effectively a measure of the average absolute monthly change, whereas RR focus on the frequency of large movements. Since the statistics are different, it is impossible to compare thresholds in the abstract.

\section{COMPARISON OF OUTCOMES}

In this section we compare the proportion of pegs identified by each scheme. For the Reinhart-Rogoff scheme the fine classification permits the use of two alternative definitions

\footnotetext{
${ }^{3}$ See Bleaney and Tian (2017) for examples.
} 
of a peg, depending on whether the frequency of large exchange rate movements is based on a $\pm 2 \%$ or a $\pm 1 \%$ threshold, which we label respectively RR2 and RR 1.4

Figure 1 shows the proportion of pegs for each year from 1971 onwards for BT, JS, RR1 and RR2. ${ }^{5}$ The JS and the RR1 schemes always identify many fewer pegs than the other two $(51.0 \%$ overall for JS; $57.4 \%$ for RR1). The other two classifications agree on the overall frequency of pegs (77.1\% for BT; $76.9 \%$ for RR2), but disagree about the trend, with BT showing a continuous downward trend but RR2 showing some recovery during the 1990s (as does R1).

Figure 2 shows the agreement rate for each pair of schemes in each year (the percentage of observations on which the schemes agree). The JS/RR2 pair has a relatively low agreement rate, averaging $67.1 \%$. The BT/JS agreement rate was around $70 \%$ from the mid-1970s to the mid-1990s, since when it has been on an increasing trend, reaching over $80 \%$ in the last few years. The BT/RR2 agreement rate has been fairly constant at around 80\%. By contrast to RR2, RR1 agrees fairly closely with JS up to 1990, after which it identifies some recovery in the proportion of pegs to about $60 \%$.

There are identifiable reasons for these results (for example the JS scheme excludes most basket pegs, crawling pegs and horizontal pegs in devaluation years if there is any variation at all about the central rate, whereas the BT scheme would tend to include them as pegs), but an interesting question is whether the precise statistic used to measure exchange

\footnotetext{
${ }^{4}$ The fine classification categories are listed in Reinhart and Rogoff $(2004$, p. 25). We omit categories 14 and 15. RR1 defines as pegs only those categories described as pegs (1, 2, 4, 5 and 7); RR2 also includes those described as "within a band not greater than $\pm 2 \%$ " $(3,6,8$ and 11). It is important to be clear that this is loose terminology: RR use data on exchange rate changes, not the range covered by the level.

${ }^{5}$ For a list of countries covered, see Appendix

Table A2.
} 
rate volatility makes much difference. ${ }^{6}$ This is the question that we address in the next Section.

${ }^{6}$ We have experimented with applying a JS rule of zero variation in the event of a realignment in the BT system; it switches about 10 percent of the observations from pegs to floats. 
Figure 1. Percentages of pegs identified by year (JS, RR1, RR2, BT)

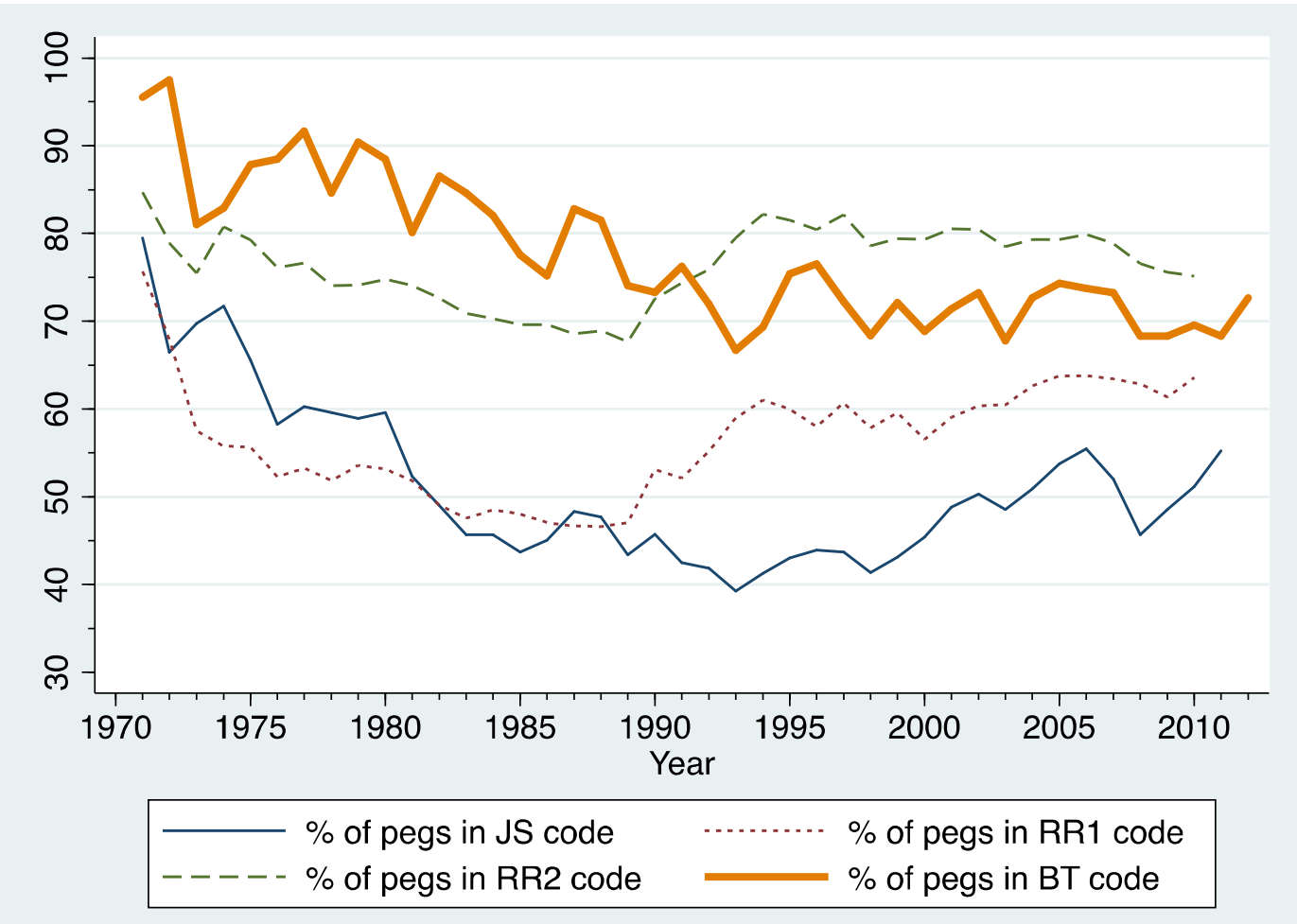

Figure 2. Pairwise agreement rates by year (BT, JS, RR1, RR2)

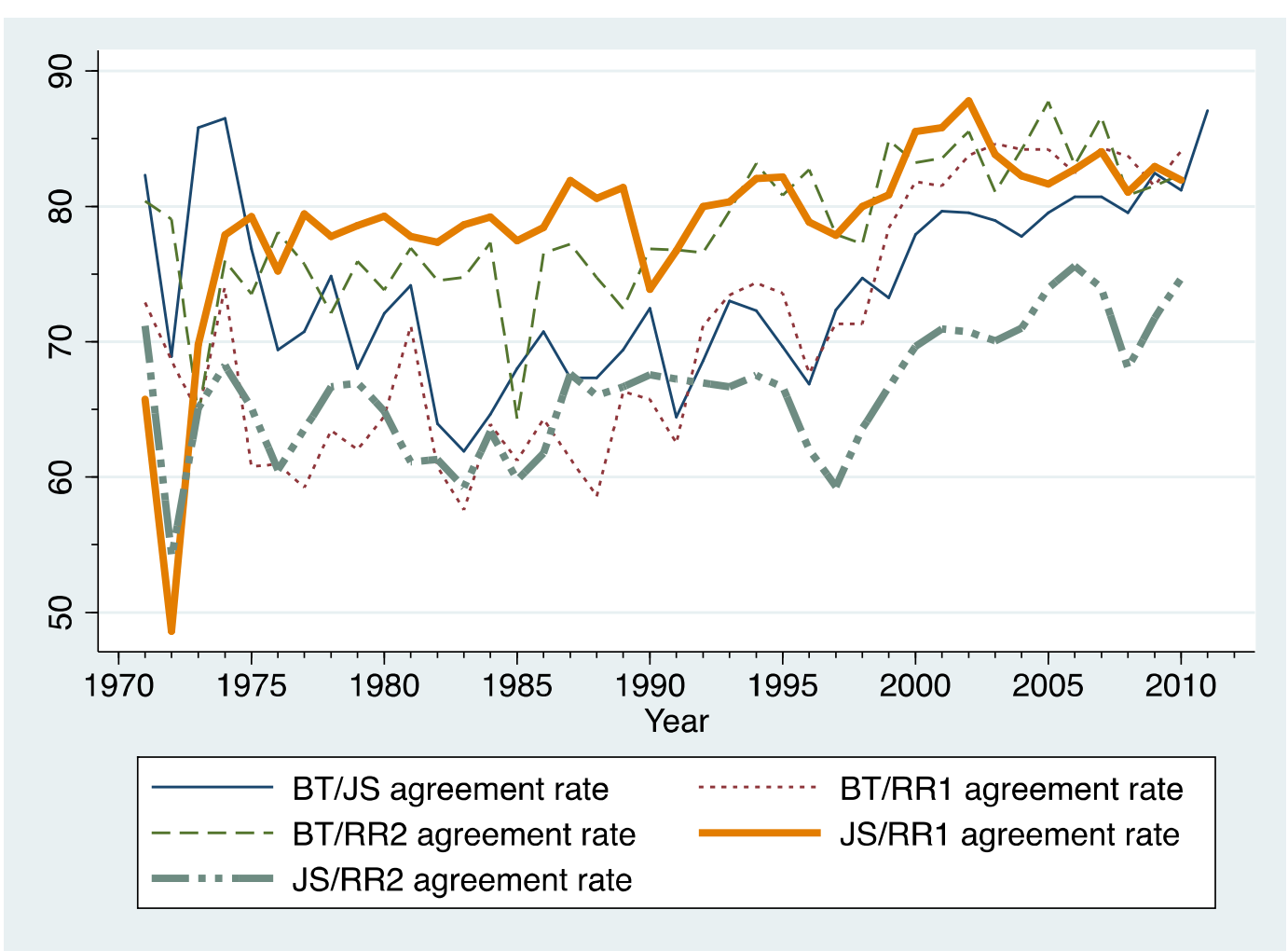




\section{COMPARING ALTERNATIVE STATISTICS}

In this Section we generate alternative statistics based on the residuals from a regression similar to that of Bleaney and Tian (2017). The point of this exercise is that the difference between these measures is purely statistical; the treatment of realignments and the method for estimating the central rate are identical, so important conceptual differences have been eliminated. If the different statistical measures produce very much the same results, then we will know that it is conceptual differences that underlie the relatively low agreement rates shown in Figure Two. If, on the other hand, alternative statistics turn out to be poorly correlated, then it would be clear that the statistical issues are important.

One statistic is a measure of the range of variation of the level of the exchange rate relative to the estimated central rate; this statistic is the equivalent of that used by Shambaugh (2004). The other statistic is the root mean square error of the regression, as in Bleaney and Tian (2017), and reflects the typical size of monthly changes in the exchange rate, again relative to the estimated central rate. ${ }^{7}$

The statistics are based on a regression identical to that of Bleaney and Tian (2017), except that we extend the period from twelve to 24 months. This is because with twelvemonth windows there is a maximum of only nine degrees of freedom (and only eight if a realignment is identified), which is rather a small number from which to generate accurate statistics. The baseline regression is:

$$
\Delta \ln E(i, C H F)_{t}=a+b \Delta \ln E(U S D, C H F)_{t}+c \Delta \ln E(E U R, C H F)_{t}+u_{t}
$$

\footnotetext{
${ }^{7}$ A statistic analogous to that used by Reinhart and Rogoff (2004) would be a measure of the frequency of large absolute residuals. We have examined such a statistic, but since the number of "large" residuals has to be an integer, it is hard to calibrate it finely enough to give a distribution of outcomes that is similar to that of the other statistics; consequently we omit it from the analysis.
} 
where $E(i, C H F)$ is the number of units of currency $i$ per Swiss franc $(U S D=$ US dollar; EUR $=$ euro) ${ }^{8}$ For some currencies other potential anchor currencies are added to the equation. ${ }^{9}$ The statistic is based on the residuals from equation (1). Realignments are dealt with in a similar way to Bleaney and Tian (2017).

For year $T$, we use monthly data from January of year $T-1$ to December of year $T$. In the case of a peg, the residuals from such a regression can be interpreted as movements in the exchange rate relative to the central rate. The root mean square error (RMSE) is the statistic analogous to that used by BT. If the residuals are cumulated, the difference between the maximum cumulated residual and the minimum cumulated residual provides an estimate of how much the level of the exchange rate has varied relative to the central rate. We call this statistic the RANGE statistic. In the special case of a single-currency horizontal peg with no realignments, it is identical to the statistic used by Shambaugh (2004). ${ }^{10}$ Appendix Table A1 summarizes the algorithms for these classification schemes.

One approach is simply to compare the two statistics across the entire sample. Table 1 shows some summary statistics for each. Both have a long upper tail, and are highly positively skewed to the left, with a mean that is higher than the $75^{\text {th }}$ percentile and at least three times higher than the median. This is because for many pegs the statistic is close to zero, and cannot be non-negative. The correlation between the RMSE and the RANGE statistics is only 0.350 , but that is strongly affected by outliers at the upper end; the rank correlation is much higher at 0.845 .

An alternative approach to comparing the statistics is to define a threshold that separates pegs from floats for each, and then to calculate how much they agree. To generate

\footnotetext{
${ }^{8}$ Alternative numeraire currencies to the Swiss franc may be used; see the discussion in Bleaney and Tian (2017).

${ }^{9}$ For details see Bleaney and Tian (2017).

${ }^{10}$ A statistic analogous to that used by RR would be based on the proportion of residuals outside a certain range.
} 
a fair measure of the extent of disagreement, we need the two thresholds to yield approximately the same proportion of pegs. ${ }^{11}$ By experimentation we have established that: a RANGE of 0.04 is roughly equivalent to an RMSE of 0.01 ; a RANGE of 0.03 is roughly equivalent to an RMSE of 0.008 ; and a RANGE of 0.02 is roughly equivalent to an RMSE of 0.006. A threshold for RANGE of 0.04, which is also that used by Shambaugh (2004), corresponds directly to a target zone of $\pm 2 \%$, and a threshold of 0.02 corresponds to a target zone of $\pm 1 \%$. We label the classifications thus generated respectively RANGE-4, RMSE-1, RANGE-3, RMSE-0.8, RANGE-2 and RMSE-0.6.

Table 2 shows the percentage of pegs identified in the whole sample by the RANGE and RMSE statistics and the agreement rate between each pair, which exceeds $90 \%$ in each case. This is much higher than the agreement rates in Figure 2, and suggests that the majority of disagreements between classifications arise from conceptual rather than statistical differences. The high level of agreement implies that it is not critical whether the statistic used is based on the range of the level of the exchange rate or on the volatility of exchange rate movements.

\footnotetext{
11 If the proportion of pegs for the two statistics is respectively $p$ and $q$, the disagreement rate cannot be less than $|p-q|$.
} 
Table 1. Summary Statistics for RMSE and RANGE

\begin{tabular}{|c|c|c|}
\hline & RMSE & Range \\
\hline Mean & 0.014 & 0.078 \\
\hline St. Dev. & 0.038 & 0.419 \\
\hline Skewness & 7.721 & 47.411 \\
\hline Median & 0004 & 0015 \\
\hline 75th Percentile & 0.013 & 0058 \\
\hline 90th Percentile & 0.030 & 0.145 \\
\hline No. Obs. & \multicolumn{2}{|c|}{6923} \\
\hline Correlation & \multicolumn{2}{|c|}{0.3500} \\
\hline Spearman's Rank Correlation & \multicolumn{2}{|c|}{0.8454} \\
\hline
\end{tabular}

Table 2. Comparing classifications based on RANGE and RMSE

\begin{tabular}{|c|c|c|c|}
\hline & \multicolumn{2}{|c|}{ Percentage of pegs } & \\
\hline Classification pair & RANGE & RMSE & Agreement rate (\%) \\
\hline & & & \\
\hline RANGE-4, RMSE-1 & 77.4 & 75.1 & 91.7 \\
\hline RANGE-3, RMSE-0.8 & 72.6 & 71.4 & 92.2 \\
\hline RANGE-2, RMSE-0.6 & 66.7 & 66.8 & 93.0 \\
\hline
\end{tabular}

Note. Sample size: 7148 observations. 


\section{WHAT STATISTICAL METHODS CAN AND CANNOT ACHIEVE}

A typical fine classification scheme would want to identify the following regimes: a currency board; a horizontal peg; a horizontal band (greater variation than a peg); a basket peg; a basket band; a crawling peg; a crawling band; a managed float; and a free float. Can this be successfully achieved by statistical methods alone? The statistical approach of Shambaugh (2004) and of Reinhart and Rogoff (2004) assumes that pegs are to a single currency, and that basket pegs can be ignored as rare, which may be true historically but cannot be guaranteed to be so in future. In the regression method of Bleaney and Tian (2017), the estimated coefficients provide information that can be used to distinguish different types of peg. A horizontal peg should have a coefficient of one for the anchor currency, and zero for the intercept and any other currency. A crawling peg to a single currency should be similar except for a non-zero intercept. In a basket peg, the currency coefficients should lie between zero and one and should add up to one (provided that all the currencies in the basket appear in the regression). Thresholds for the RMSE need to be decided for pegs to be distinguished from bands, and bands from floats. What statistical methods cannot do is to distinguish a

currency board from a conventional peg that happens not to have been devalued for a long time; that requires additional information.

When it comes to floats, it is important to recognise that bilateral exchange rate volatility increases with distance, and that at the aggregate level both nominal and real effective exchange rate volatility increase with remoteness (weighted-average distance from trading partners) (Bleaney and Tian, 2012; Bravo-Ortega and di Giovanni, 2006). Consequently the natural level of volatility under free floating is lower for less remote currencies. When Reinhart and Rogoff (2004) calibrate the "typical" behaviour of freely floating currencies from the statistics for the currencies of Australia, Germany, Japan, New 
Zealand and the United Kingdom against the US dollar, and then use this to derive a threshold between managed and free floats, they fail to take account of the fact that these are all widely separated currency pairs. Consequently they end up virtually never classifying less remote floaters like Canada and the UK, which are relatively close to a major trading partner (the USA and the Euro Area respectively), as free floats. In other words, the threshold chosen by Reinhart and Rogoff is appropriate only for more remote currencies, because a volatility statistic that would seem to indicate a managed float for a more remote currency may be entirely typical of free floating for a less remote one.

Table 3 illustrates the point. The average statistic (either RANGE or RMSE) for more remote floating currencies in Table 3 is significantly higher than for the less remote ones, with the $t$-statistic of the average difference exceeding six. That implies that any purely statistical method of distinguishing managed from free floats should take remoteness into account, although exactly how is not entirely clear. One might prefer instead to rely on other information, as is done in the IMF's de facto classification.

Thus it is clear that, although statistics are a good guide to the classification of exchange rate regimes, they are not the answer to everything. Their most important limitation, however, is that they cannot answer conceptual questions, such as how narrowly controlled an exchange rate has to be to constitute a peg. Statistical analysis can help to identify realignments, but cannot tell us how to treat them in a classification. Different classification schemes not only use different statistics but are also based on different conceptual approaches, and this point needs to be more widely appreciated by the users of these classifications. 
Table 3. Statistics for more remote and less remote floating currencies 1997-2011

\begin{tabular}{|c|c|c|c|c|}
\hline \multirow[b]{2}{*}{ country } & \multicolumn{2}{|c|}{ RANGE } & \multicolumn{2}{|c|}{ RMSE } \\
\hline & mean & std deviation & mean & std deviation \\
\hline & \multicolumn{4}{|c|}{ less remote } \\
\hline Canada & 0.0783 & 0.0337 & 0.0206 & 0.0071 \\
\hline Norway & 0.0658 & 0.0446 & 0.0166 & 0.0058 \\
\hline Sweden & 0.0591 & 0.0254 & 0.0153 & 0.0061 \\
\hline \multirow[t]{2}{*}{ United Kingdom } & 0.0659 & 0.0393 & 0.0171 & 0.0055 \\
\hline & \multicolumn{4}{|c|}{ more remote } \\
\hline Australia & 0.0903 & 0.0425 & 0.0242 & 0.0044 \\
\hline Chile & 0.0970 & 0.0570 & 0.0261 & 0.0073 \\
\hline Japan & 0.0940 & 0.0334 & 0.0246 & 0.0079 \\
\hline New Zealand & 0.1020 & 0.0498 & 0.0275 & 0.0059 \\
\hline $\begin{array}{c}\text { Difference in } \\
\text { means } \\
(t \text {-statistic })\end{array}$ & $\begin{array}{c}0.0285 \\
(6.57)\end{array}$ & & $\begin{array}{c}0.00822 \\
(6.46)\end{array}$ & \\
\hline
\end{tabular}

Notes. For description of statistics see text. The difference in means is between the more remote and the less remote countries.

\section{CONCLUSIONS}

Even though de facto exchange rate classification schemes have been in use for some years, they have shown little sign of converging towards agreement with one another. This is because there are several dimensions to the differences in the construction of these schemes: they differ in the statistic used to measure exchange rate volatility, the threshold values of this statistic that form the boundaries between regimes, and how realignments are treated. Nevertheless statistical methods can go a long way towards identifying an exchange rate regime. For example, independent floats have clearly different characteristics from pegs. Using the regression method, basket pegs and crawls can be picked up. 
We have shown that, with similarly calibrated thresholds and differences in conceptual approaches as far as possible ironed out, different statistics produce similar results, with over 90 percent agreement. That implies that economic rather than statistical issues are mainly responsible for the observed disagreements between schemes, and that users need to be more conscious of the economic assumptions underlying a given scheme. With a better understanding of these issues, there would be a greater prospect of the profession moving towards consensus about the optimal scheme, and researchers would be in a better position to choose a classification that best suits their purposes.

Nevertheless statistical methods have some clear limitations, where they need to be supplemented with other information or judgement. A currency board is not statistically distinguishable from a long-running conventional peg with no history of realignments just using exchange rate data. Tightly managed floats may be hard to distinguish from some sort of target zone with a wider band than that of a normal peg, and loosely managed ones may be hard to distinguish from free floats. This issue is particularly acute for countries that are not very remote from their trading partners because, as we have shown, these countries have intrinsically lower exchange rate volatility than others.

\section{References}

Alberola, E., A. Erce and J.M. Serena (2016), International reserves and gross capital flows dynamics, Journal of International Money and Finance 60, 151-171

Bénassy-Quéré, A., B. Coeuré and V. Mignon (2006), On the identification of de facto currency pegs, Journal of the Japanese and International Economies 20, 112-127

Bleaney, M.F. and M. Francisco (2007), Classifying exchange rate regimes: a statistical analysis of alternative methods, Economics Bulletin 6 (3), 1-6.

Bleaney, M.F., H.A. Lee and T. Lloyd (2013), Testing the trilemma: exchange rate regimes, capital mobility and monetary independence, Oxford Economic Papers 65, 876-897 
Bleaney, M.F. and M. Tian (2012), Currency networks, bilateral exchange rate volatility and the role of the US dollar, Open Economies Review 23 (5), 785-803

Bleaney, M.F. and M. Tian (2017), Measuring exchange rate flexibility by regression methods, Oxford Economic Papers, forthcoming

Bleaney, M.F., M. Tian and L. Yin (2016), Global trends in the choice of exchange rate regime, Open Economies Review 26, 71-85

Bravo-Ortega, C. and J. di Giovanni (2006), Remoteness and real exchange rate volatility, IMF Staff Papers 53 (Special Issue), 115-132

Eichengreen, B. and R. Razo-Garcia (2013), How reliable are de facto exchange rate regime classifications? International Journal of Finance and Economics 18, 216-239

Erdem, F.P.and E. Özmen (2015), Exchange rate regimes and business cycles: an empirical Investigation, Open Economies Review 26(5), 1041-1058

Frankel, J. and S.-J. Wei (1995), Emerging currency blocs, in The International Monetary System: Its Institutions and its Future, ed. H. Genberg (Berlin, Springer)

Frankel, J. and S.-J. Wei (2008), Estimation of de facto exchange rate regimes: synthesis of the techniques for inferring flexibility and basket weights, IMF Staff Papers 55 (3), 384-416

Ghosh, A.R., A.-M. Gulde and H.C. Wolf (2002), Exchange Rate Regimes: Causes and Consequences, Cambridge, MA: MIT Press.

Giavazzi, F. and M. Pagano (1988) The advantage of tying one's hands, European Economic Review 32, 1055-1082

Klein, M.W. and J.C. Shambaugh (2010), Exchange Rate Regimes in the Modern Era, Cambridge, Mass.: MIT Press.

Levy-Yeyati, E. and F. Sturzenegger (2005), Classifying exchange rate regimes: deeds versus words, European Economic Review 49 (6), 1173-1193

Lin, H.-Y. and H.-P. Chu (2013), Are fiscal deficits inflationary? Journal of International Money and Finance 32, 214-233

Mandilaras, A. (2015), The international policy trilemma in the post-Bretton Woods era, Journal of Macroeconomics 44, 18-32

Martin, F.E. (2016), Exchange rate regimes and current account adjustment: an empirical investigation, Journal of International Money and Finance 65, 69-93

Reinhart, C.M. and Rogoff, K. (2004), The modern history of exchange rate arrangements: a re-interpretation, Quarterly Journal of Economics 119 (1), 1-48 
Rose, A.K. (2011), Exchange rate regimes in the modern era: fixed, floating and flaky, Journal of Economic Literature 49 (3), 652-672

Shambaugh, J. (2004), The effects of fixed exchange rates on monetary policy, Quarterly Journal of Economics 119 (1), 301-352

Tavlas, G., H. Dellas and A.C. Stockman (2008), The classification and performance of alternative exchange-rate systems, European Economic Review 52, 941-963

\section{APPENDIX - DETAILED COMPARISON OF CLASSIFICATION SCHEMES}

In this Appendix we summarise and evaluate a number of classification schemes that are exclusively based on exchange rate data.

Ghosh et al. (2002) [hereafter GGW]. A set of annual scores $(s)$ is constructed based on the mean $(\mu)$ and standard deviation $(\sigma)$ of monthly rates of exchange rate depreciation against each of a number of reference currencies; the minimum of these values of $s$ identifies the one to which the currency is potentially pegged, and all the above-minimum values are discarded. Specifically the statistic is:

$$
s=\sqrt{\mu^{2}+\sigma^{2}}
$$

Countries' regimes are recorded as pegged, intermediate or floating based on whether this statistic is low, intermediate or high. The distribution of regimes is recorded, and the thresholds for $s$ in each year are chosen so as to yield exactly the same distribution as in the IMF de jure classification in that year.

Evaluation: a horizontal single-currency peg should yield a low value of $s$, as intended, but a realignment during the year would raise both $\mu^{2}$ and $\sigma^{2}$, in which case a realignment year might be classified as intermediate or even floating. Basket pegs and crawling pegs will also tend to have higher values of $s$ than single-currency pegs. The use of different thresholds in 
different years is unsatisfactory, as is the choice of the de jure classification as the basis for determining them, since the main point of a de facto classification is to establish if the de jure classification is correct.

Shambaugh (2004) [hereafter termed JS]. A reference currency is identified. If the maximum and minimum of the log of the exchange rate against the reference currency (the US dollar being the default) do not differ by more than 0.04 over the calendar year, that observation is a peg. Alternatively, if the 0.04 threshold is exceeded, the observation is still a peg if the log of the exchange rate is unchanged in eleven months out of twelve. Thus effectively the level of the exchange rate is allowed to vary by $\pm 2 \%$, or alternatively by a realignment of any size in one month and $0 \%$ in the remaining eleven months, for a peg to be coded.

Evaluation: the statistical criterion is the range of variation about the central rate, which has the merit that it is closely related to the width of the target zone. There is the same problem with basket pegs and crawling pegs as in the case of Ghosh et al. (2002). The switch to a zero range in the event of a realignment implies that many pegs may not be identified as such in realignment years. For these reasons the frequency of pegs is likely to be underestimated.

Reinhart and Rogoff (2004) [hereafter termed RR]. Movements of the log of the exchange rate against various reference currencies are analysed, and as in GGW the reference currency that yields the lowest volatility is used. Where available, the exchange rate in the parallel market rather than the official rate is used. If, over a five-year period from years $T-4$ to $T$, more than $80 \%$ of monthly changes in the log of the exchange rate against any of the reference currencies fall within the range \pm 0.01 , the exchange rate regime in all of the years $T-4$ to $T$ is classified as some form of peg. Alternatively, even if this criterion is not met, if the change in the exchange rate is zero for four months or more, it is classified as a peg for 
those months. If fewer than $80 \%$ of monthly changes fall within the range \pm 0.01 , but more than $80 \%$ fall within the range \pm 0.02 , the regime is classified as a band. If the exchange rate moves by more than $40 \%$ in a year, that observation is placed in a separate "freely falling" category (these observations are omitted from the comparison with other schemes). Thus the scheme focuses on the upper tail of the distribution of monthly exchange rate movements, and specifically the proportion that exceed either $1 \%$ or $2 \%$ in absolute value.

Evaluation: The statistic used represents the general idea that exchange rate volatility is lower under pegs and therefore that there are fewer large movements, and its relationship to the width of a target zone is unclear since it concerns the frequency distribution of exchange rate changes rather than a range for the level. Basket pegs may well not meet the criteria for a peg, but crawling pegs should do so if the crawl is slow enough. ${ }^{12}$ Realignments, if not too frequent, should not cause any particular problem, since they represent just another tail observation. The proportion of pegs recorded will depend entirely on the threshold chosen for the statistic.

Bleaney and Tian (2017) [hereafter termed BT]. The scheme is based on the root mean square residual (RMSE) from a regression similar to that of Frankel and Wei (1995) for identifying basket pegs. For each calendar year, the change in the log of the official exchange rate against the Swiss franc (the chosen numéraire currency) is regressed on the change in the log of the US dollar and of the euro against the Swiss franc. Occasionally, other reference currencies are added. ${ }^{13}$ If the RMSE from this regression is less than 0.01 , that country-year observation is coded a peg. If the RMSE is greater than 0.01 , twelve new

\footnotetext{
${ }^{12}$ Reinhart and Rogoff (2004, pp. 42-3) claim that missing a few de facto basket pegs is historically "almost certainly not a major issue". Whether or not this is true of the past, it might not be true in the future, as illustrated, for example, by China's announced shift from a US dollar peg to a basket peg in December 2015. ${ }^{13}$ See Bleaney and Tian (2016) for details. A similar regression approach to regime classification has been suggested by Benassy-Quéré et al. (2006) and Frankel and Wei (2008), but they focus on the estimated coefficients rather than the goodness of fit.
} 
regressions are estimated each including a dummy variable for a particular month as a test for a realignment. If the F-statistic for the most significant of these dummy variables (April, say) is less than 30, the regime is coded a float. If the F-statistic for April is greater than 30, and the RMSE is less than 0.01 , the observation is coded a peg with a realignment; otherwise it is a float.

Evaluation: the regression approach should cater for basket pegs (through the regression coefficients) or crawls (through the intercept), but errors may arise from the small number of degrees of freedom in each regression. The use of dummy variables solves the problem of realignments, provided that there is not more than one per year. The statistic used is different from that of Reinhart and Rogoff (2004), since it captures the average size of movements in the exchange rate rather than the proportion of large ones, but as in their case the statistic is not closely related to the width of the target zone.

Summary: the Shambaugh system comes closest to the notion of a peg as a narrow target zone for the exchange rate, but underestimates the proportion of pegs for various reasons. The other three systems use statistics which capture the general idea that pegs have lower volatility, but whose relationship to the width of the target zone is unclear. 
Appendix Table A1. Algorithms for a binary classification using RANGE and RMSE

\begin{tabular}{|c|l|}
\hline Scheme & \multicolumn{1}{|c|}{ Description of algorithm for regime classification in year T } \\
\hline RANGE-4 & $\begin{array}{l}\text { Regress monthly change in ln exchange rate against Swiss franc on change in } \\
\text { ln US\$ and euro rates against Swiss franc for January of year T-1 to December } \\
\text { of year T. Repeat procedure 24 times, each with one monthly dummy added. } \\
\text { If maximum F-statistic for addition of any monthly dummy > 30, use that } \\
\text { regression in place of the original. Cumulate the residuals from the chosen } \\
\text { regression and calculate the difference between the maximum and the } \\
\text { minimum of the cumulated residuals. Code as peg if this difference }<0.04 . \\
\text { Occasionally other reference currencies are added (for the same cases as BT). }\end{array}$ \\
\hline RANGE-3 & As RANGE-4, except at last step code as peg if difference < 0.03. \\
\hline RANGE-2 & As RANGE-4, except at last step code as peg if difference < 0.02. \\
\hline RMSE-1 & $\begin{array}{l}\text { Generate residuals as for RANGE-4. Code as peg if the root mean square } \\
\text { residual is }<0.01 .\end{array}$ \\
\hline RMSE-0.8 & $\begin{array}{l}\text { Generate residuals as for RANGE-4. Code as peg if the root mean square } \\
\text { residual is }<0.008 .\end{array}$ \\
\hline RMSE-0.6 & $\begin{array}{l}\text { Generate residuals as for RANGE-4. Code as peg if the root mean square } \\
\text { residual is }<0.006 .\end{array}$ \\
\hline
\end{tabular}


Appendix Table A2. Sample of countries (182)

\begin{tabular}{|c|c|}
\hline $\begin{array}{c}\text { Developed Countries } \\
\qquad(\mathbf{3 6})^{1}\end{array}$ & $\begin{array}{l}\text { Euro Area (18) } \\
\text { Austria, Belgium, Cyprus, Estonia, Finland, France, Germany, Greece, } \\
\text { Ireland, Italy, Latvia, Luxembourg, Malta, Netherlands, Portugal, Slovak } \\
\text { Rep., Slovenia, Spain; } \\
\text { Major Advanced Economies ( } \mathbf{7}, \mathbf{3} \text { of them in Euro Area) } \\
\text { Canada, France, Germany, Italy, Japan, United Kingdom, United States; } \\
\text { Other Advanced Economies (14) } \\
\text { Australia, Czech Rep., Denmark, Hong Kong SAR, Iceland, Israel, Korea, } \\
\text { Lithuania, New Zealand, Norway, San Marino, Singapore, Sweden, } \\
\text { Switzerland. }\end{array}$ \\
\hline $\begin{array}{c}\text { Emerging Market } \\
\text { Countries }(\mathbf{1 8})^{2}\end{array}$ & $\begin{array}{l}\text { Brazil, Chile, China, Colombia, Egypt, Hungary, India, Indonesia, } \\
\text { Malaysia, Mexico, Morocco, Peru, Philippines, Poland, Russia, South } \\
\text { Africa, Thailand, Turkey. }\end{array}$ \\
\hline $\begin{array}{l}\text { Other Developing } \\
\text { Countries (128) }\end{array}$ & $\begin{array}{l}\text { Commonwealth of Independent States (11) } \\
\text { Armenia, Azerbaijan, Belarus, Georgia, Kazakhstan, Kyrgyz Rep., } \\
\text { Moldova, Tajikistan, Turkmenistan, Ukraine, Uzbekistan; } \\
\text { Asia (19) } \\
\text { Bangladesh, Bhutan, Brunei, Cambodia, Fiji, Kiribati, Laos, Maldives, } \\
\text { Micronesia, Mongolia, Myanmar, Nepal, Papua New Guinea, Samoa, } \\
\text { Solomon Islands, Sri Lanka, Tonga, Vanuatu, Vietnam; } \\
\text { Europe (8) } \\
\text { Albania, Bosnia and Herzegovina, Bulgaria, Croatia, Macedonia, } \\
\text { Montenegro, Romania, Serbia; } \\
\text { Latin America and the Caribbean (28) } \\
\text { Antigua and Barbuda, Argentina, Aruba, Bahamas, Barbados, Belize, } \\
\text { Bolivia, Costa Rica, Dominica, Dominican Rep., El Salvador, Grenada, } \\
\text { Guatemala, Guyana, Haiti, Honduras, Jamaica, Netherlands Antilles, } \\
\text { Nicaragua, Panama, Paraguay, St. Kitts and Nevis, St. Lucia, St. Vincent } \\
\text { and the Grenadines, Suriname, Trinidad and Tobago, Uruguay, } \\
\text { Venezuela; } \\
\text { Middle East, North Africa, Afghanistan, and Pakistan (19) } \\
\text { Afghanistan, Algeria, Bahrain, Djibouti, Iran, Iraq, Jordan, Kuwait, } \\
\text { Lebanon, Libya, Mauritania, Oman, Pakistan, Qatar, Saudi Arabia, Sudan, } \\
\text { Tunisia, United Arab Emirates, Yemen; } \\
\text { Sub-Saharan Africa (43) } \\
\text { Angola, Benin, Botswana, Burkina Faso, Burundi, Cameroon, Cape } \\
\text { Verde, Central African Rep., Chad, Comoros, Congo, Cote d'Ivoire, } \\
\text { Democratic Rep. of the Congo, Equatorial Guinea, Eritrea, Ethiopia, } \\
\text { Gabon, Gambia, Ghana, Guinea, Guinea-Bissau, Kenya, Lesotho, Liberia, } \\
\text { Madagascar, Malawi, Mali, Mauritius, Mozambique, Namibia, Niger, } \\
\text { Nigeria, Rwanda, Sao Tome and Principe, Senegal, Seychelles, Sierra } \\
\text { Leone, Somalia, Swaziland, Tanzania, Togo, Uganda, Zambia. }\end{array}$ \\
\hline
\end{tabular}

